Check for updates

Cite this: Phys. Chem. Chem. Phys., 2018, 20, 20821

Received 19th June 2018

Accepted 23rd July 2018

DOI: $10.1039 / c 8 c p 03881 c$

rsc.li/pccp

\title{
Supramolecular interaction of non-racemic benzimidazolium based ion pairs with chiral substrates $\dagger$
}

\author{
Salma Mumtaz, ${ }^{\text {ab }}$ Israel Cano, (D)*b Nargis Mumtaz, ${ }^{a}$ Ahmed Abbas, ${ }^{c}$ \\ Jairton Dupont (D) *bd and Humaira Yasmeen Gondal (D)*a
}

\begin{abstract}
A series of novel benzimidazolium-based non-racemic ionic liquids (ILS) was synthesized from low-cost chiral terpenoid alcohols and fully characterized by the use of a wide variety of techniques, such as DSC, ESI-MS, ATR FT-IR, polarimetry as well as ${ }^{1} \mathrm{H}$ and ${ }^{13} \mathrm{C}$ NMR spectroscopy. The ILs were investigated as chiral shift agents for the chiral recognition of racemic mixtures of Mosher's acid potassium salt by ${ }^{19} \mathrm{~F}$ NMR spectroscopy, leading to high splitting values of the $\mathrm{CF}_{3}$ signal. Supramolecular interactions between salt and $\mathrm{H}-\mathrm{C} 2$ of chiral benzimidazolium cation are responsible for the chiral recognition, as was demonstrated by experimental evidences. Indeed, the enantiomeric excess value of enantioenriched substrates depends mainly on the strength of the contact ion pairs.
\end{abstract}

\section{Introduction}

Over the past few years, ionic liquids (ILs) have attracted much interest due to their exceptional physical and chemical properties, such as reasonable thermal stability, lack of measurable vapor pressure, high conductivity, appropriate viscosity, catalytic activity and ease recovery and recyclability. ${ }^{1}$ In particular, chiral ILs deserve a special attention due to their unique ability to act as organocatalysts, coordinating ligands and/or solvents for enantioselective transformations. ${ }^{2-4}$ These compounds can be prepared by asymmetric synthesis, but protocols based on the use of inexpensive and pre-existing chiral substrates derived from the chiral pool are more attractive to scale-up the synthesis. Consequently, most reported chiral ILs are obtained from naturally available chiral moieties, such as amino acids, ${ }^{5}$ carbohydrates, ${ }^{6}$ terpenoids and alkaloids. ${ }^{7}$ Chiral ILs exhibit applications in ligand exchange chromatography, ${ }^{8}$ stereoselective polymerization, ${ }^{9}$ liquid and gas chromatography, ${ }^{10}$ capillary electrophoresis, ${ }^{10 e, 11}$

\footnotetext{
${ }^{a}$ Department of Chemistry, University of Sargodha, Sargodha, 40100, Pakistan. E-mail: hygondal@yahoo.com

${ }^{b}$ GSK Carbon Neutral Laboratory for Sustainable Chemistry, University of Nottingham, NG7 2GA, Nottingham, UK.

E-mail: israel.canorico@nottingham.ac.uk

${ }^{c}$ H.E.J. Research Institute of Chemistry, ICCBS, University of Karachi, Karachi, 75270, Pakistan

${ }^{d}$ Laboratory of Molecular Catalysis, Institute of Chemistry, UFRGS, Av. Bento Gonçalves, 9500, Porto Alegre 91501-970, RS, Brazil.

E-mail: jairton.dupont@ufrgs.br

$\dagger$ Electronic supplementary information (ESI) available: General experimental procedures, synthetic procedures, characterization of new compounds, and ${ }^{1} \mathrm{H}$ NMR and ${ }^{13} \mathrm{C}$ NMR spectra. See DOI: $10.1039 / \mathrm{c} 8 \mathrm{cp} 03881 \mathrm{c}$
}

and as organocatalysts, coordinating ligands and/or solvents for asymmetric synthesis., ${ }^{3,42}$ In addition, chiral ILs have also proven to be very effective as chiral shift agents in NMR spectroscopy for the discrimination of racemic mixtures. ${ }^{4,12,13}$ These analytical chiral separations are accomplished by in situ generation of temporary diastereomeric adducts through hydrogen bonds, halogen bonding or ionic, dipole-dipole, ion-dipole, van der Waals and $\pi-\pi$ stacking interactions. ${ }^{14}$ The first application of chiral ILs as shift agents in NMR spectroscopy was described by Wasserscheid et al. in 2002, where an ephedrine derived IL was used to determine the enantiomeric excess (ee) of a racemic mixture of Mosher's acid sodium salt by a simple integration of NMR signals. ${ }^{15}$ Since then, many examples have been reported employing chiral ILs as shift reagents, ${ }^{4,12,13}$ displaying moderate to high enantio-discrimination levels. However, little is known about the supramolecular interaction between racemic substrates and the non-racemic IL ion pair.

Therefore, in order to contribute towards the understanding upon the supramolecular interactions that can be established between racemic substrates and non-racemic ILs, we have designed and prepared a new family of chiral ILs and explored their potential use as chiral recognition agents. Herein we report the synthesis of a new family of benzimidazolium-based chiral ILs prepared from commonly available and inexpensive chiral terpene alcohols such as (+)-menthol, (+)-fenchyl alcohol and (+)-isopinocampheol (Fig. 1). The obtained enantiomerically pure ILs were characterized by DSC, ATR FT-IR, ESI-MS, polarimetry along with ${ }^{1} \mathrm{H}$ and ${ }^{13} \mathrm{C}$ NMR spectroscopy. In addition, the new ILs were studied as chiral shift agents for the chiral recognition of racemic mixtures of Mosher's acid potassium 
<smiles>CC(C)[C@H]1CC[C@@H](C)C[C@H]1O</smiles>

1a<smiles>CC1(C)[C@@H](O)[C@@H]2CC[C@]1(C)C2(C)C</smiles>

$1 b$

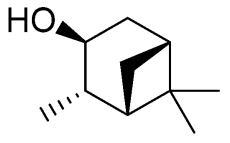

1c
Fig. 1 Natural secondary alcohols 1a: (+)-menthol; 1b: (+)-fenchyl alcohol; 1c: (+)-isopinocampheol.

salt. Experimental studies enabled us to elucidate the nature of the interaction between the non-racemic ILs and the racemic Mosher's acid potassium salt. Finally, the ILs demonstrated their ability for the determination of the enantiomeric excess of enantioenriched samples.

\section{Results and discussion}

\section{Synthesis and characterization of the new benzimidazolium- based chiral ILs}

The benzimidazolium-based chiral ILs 4-7 were obtained through a three step synthetic route (Scheme 1 and Sections 2 and $3, \mathrm{ESI} \dagger)$. The reaction of paraformaldehyde with the chiral alcohols 1a-c generated the corresponding acetals 2a-c, which were reacted in situ with acetyl chloride to give the alkoxymethyl halides 3a-c (Scheme 1a). ${ }^{16}$ Next, the non-racemic ILs 4a-c were synthesized in good yields (Scheme $1 \mathrm{~b}$ ) by reaction of 3a-c with 1-methylbenzimidazole at room temperature (RT). This step is very fast since the reaction mixture was immediately transformed in a semisolid which was further stirred for $30 \mathrm{~min}$ to ensure the complete reaction. Finally, the anion exchange by reaction with sodium tetrafluoroborate $\left(\mathrm{NaBF}_{4}\right)$, potassium hexafluorophosphate $\left(\mathrm{KPF}_{6}\right)$ and lithium bistrifluoromethanesulfonimidate ( $\left.\operatorname{LiNTf}_{2}\right)$ produced the non-racemic ILs 5-7a-c (Scheme 1c).

The obtained non-racemic ILs 4-7 were completely characterized by Fourier-Transform Infrared (ATR FT-IR) spectroscopy, electrospray ionization mass spectrometry (ESI-MS), and ${ }^{1} \mathrm{H}$ and ${ }^{13} \mathrm{C}$ NMR spectroscopy (for further details see ESI $\dagger$ ), whereas their melting point was studied by differential scanning calorimetry (DSC). Table 1 displays the most important physical properties of 4-7.

All synthesized ILs are non-racemic, as it is confirmed by their specific rotation $\left([\alpha]_{\mathrm{D}}^{20}\right)$. We observed a trend in the $[\alpha]_{\mathrm{D}}^{20}$ values of ILs depending on the chiral building block ((+)-menthol, 1a; (+)-fenchyl alcohol, $\mathbf{1 b}$; (+)-isopinocampheol, 1c) employed for their synthesis. In the case of (+)-menthol ILs $\mathbf{4 a - 7 a}$, there is a large difference between the specific rotation of $\mathrm{Cl}^{-}$and $\mathrm{BF}_{4}^{-}$based salts and

a) Synthesis of Chiral Alkoxymethyl Halides 3a-c from Chiral Alcohols 1a-c

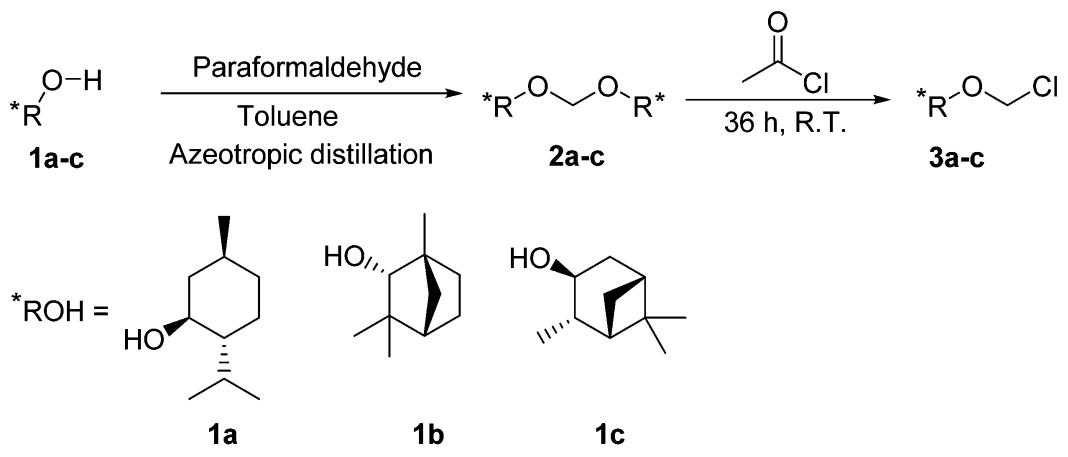

b) Synthesis of Chiral lonic Liquids $4 a-c$

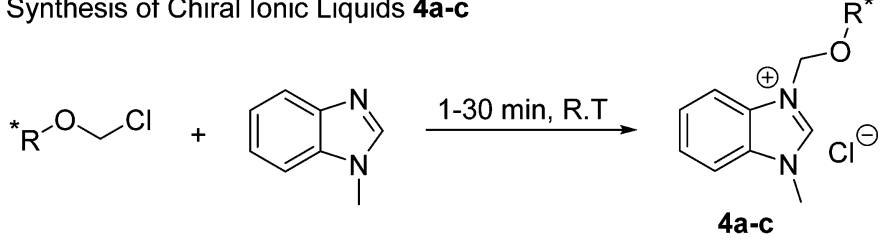

c) Synthesis of Chiral Ionic Liquids 5a-c, 6a-c and 7a-c by anion exchange reaction

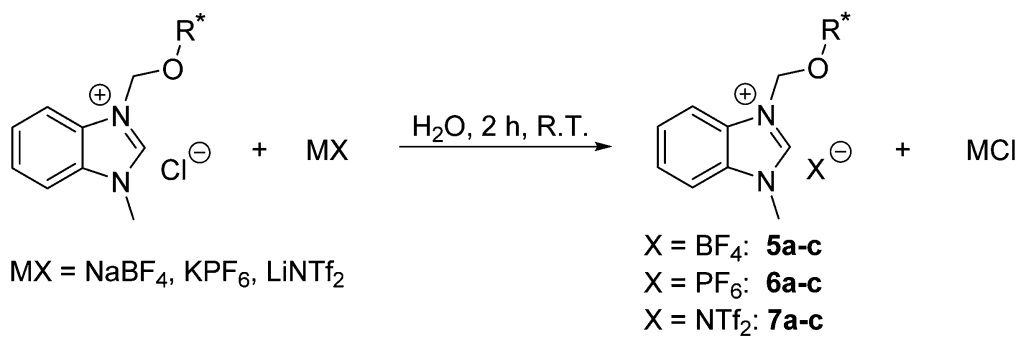

Scheme 1 Synthetic route for non-racemic ILs 4-7a-c from chiral alcohols 1a-c. 
Table 1 Physical properties of synthesized non-racemic ILs $4-7^{a}$

\begin{tabular}{llllll}
\hline Entry & $\begin{array}{l}\text { Non-racemic } \\
\text { IL }\end{array}$ & $\begin{array}{l}\text { Physical } \\
\text { state }^{b}\end{array}$ & $\begin{array}{l}\text { Yield } \\
(\%)\end{array}$ & $\begin{array}{l}\mathrm{Mp}^{c} \\
\left({ }^{\circ} \mathrm{C}\right)\end{array}$ & $\begin{array}{l}{[\alpha]_{\mathrm{D}}^{20} d} \\
\left(\mathrm{deg} \mathrm{mL} \mathrm{g}^{-1} \mathrm{dm}^{-1}\right)\end{array}$ \\
\hline 1 & $\mathbf{4 a}$ & White solid & 97 & 127 & +136.5 \\
2 & $\mathbf{5 a}$ & White solid & 99 & 132 & +147.5 \\
3 & $\mathbf{6 a}$ & White solid & 99 & 123 & +94.5 \\
4 & $\mathbf{7 a}$ & Light brown oil & 99 & - & +96.5 \\
5 & $\mathbf{4 b}$ & White solid & 95 & 124 & +39.8 \\
6 & $\mathbf{5 b}$ & White solid & 98 & 122 & +38.2 \\
7 & $\mathbf{6 b}$ & White solid & 99 & 147 & +45.0 \\
8 & $\mathbf{7 b}$ & Light brown oil & 99 & - & +22.5 \\
9 & $\mathbf{4 c}$ & White solid & 93 & 122 & +37.8 \\
10 & $\mathbf{5 c}$ & White solid & 98 & 124 & +41.0 \\
11 & $\mathbf{6 c}$ & White solid & 99 & 124 & +55.0 \\
12 & $\mathbf{7 c}$ & Light brown oil & 98 & - & +30.0
\end{tabular}

${ }^{a}$ Uncertainties of measured values: yield, $\pm 1 \%$; mp, $\pm 0.5{ }^{\circ} \mathrm{C} ;[\alpha]_{\mathrm{D}}^{20}$, $\pm 2 \% .{ }^{b}$ Physical state at $20{ }^{\circ} \mathrm{C} .{ }^{c}$ Mp: melting point determined by DSC. ${ }^{d}[\alpha]_{\mathrm{D}}^{20}: c=4 \mathrm{mg} \mathrm{mL}-1, \mathrm{MeOH}, 20{ }^{\circ} \mathrm{C}$.

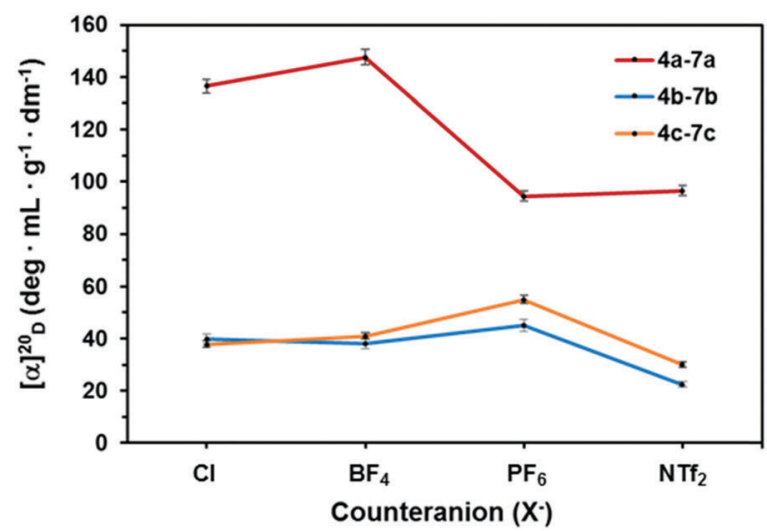

Fig. 2 Graphical representation of specific rotation $\left([\alpha]_{D}^{20}\right)$.

those of $\mathrm{PF}_{6}{ }^{-}$and $\mathrm{NTf}_{2}{ }^{-}$ILs (Fig. 2). However, for $\mathbf{4 b}-\mathbf{b} \mathbf{b}$ and 4c-7c the $[\alpha]_{\mathrm{D}}^{20}$ values of $\mathrm{Cl}^{-}$based salts were found to be similar to those of $\mathrm{BF}_{4}{ }^{-}$and lower than $\mathrm{PF}_{6}{ }^{-}$based non-racemic ILs, whereas $\mathrm{NTf}_{2}{ }^{-}$compounds showed the lowest values of $[\alpha]_{\mathrm{D}}^{20}$ (Fig. 2).
On the other hand, DSC revealed a melting point (mp) in the range of $122-147{ }^{\circ} \mathrm{C}$ for 4-6 (Table 1), while all $\mathrm{NTf}_{2}$ ILs are liquid at RT.

\section{Chiral recognition of racemic mixtures of Mosher's acid potassium salt by the new benzimidazolium-based chiral ILS}

The potential for chiral recognition of synthesized ILs was evaluated through the study of the diastereomeric interaction between 4-7 and a racemic mixture of Mosher's acid potassium salt. For this purpose, various mixtures of Mosher's acid potassium salt and the corresponding chiral IL were analyzed by ${ }^{19} \mathrm{~F}$ NMR spectroscopy in order to observe splitting of $\mathrm{CF}_{3}$ signal. Each chiral IL was mixed with the racemic mixture of salt in a specific deuterated solvent at RT, sonicated for 3-5 seconds if required and then filtered.

Different concentrations of $\mathbf{6 b}$ regarding the racemic salt were tested in order to find the optimal amount of chiral IL required for maximum splitting of $\mathrm{CF}_{3}$ signal of racemic Mosher's acid potassium salt. The influence of $\mathbf{6 b}$ concentration on the degree of $\mathrm{CF}_{3}$ signal splitting is represented graphically in Fig. 3. Two equiv. of $\mathbf{6 b}$ was the best ratio to obtain the maximum splitting $(23.7 \mathrm{~Hz}$, Fig. 3), whereas the extent of the splitting decreased for higher concentrations of 6b. The influence of IL concentration on the magnitude of chemical shift difference is well known and has been previously described by several authors. ${ }^{5 d, 15,17}$

The nature of the interaction between the chiral ILs and the racemic Mosher's acid potassium salt was investigated by experimental studies. The racemic salt could interact with the IL through hydrogen bonding with the $\mathrm{H}-\mathrm{C} 2$ of the enantiopure imidazolium cation. ${ }^{18}$ However, an interaction by $\pi-\pi$ stacking between the phenyl groups of both compounds is also likely. ${ }^{4 b}$ Therefore, we prepared the chiral ILs 8 and 9 in order to investigate the type of interaction between the different species in solution (Fig. 4).

Benzimidazolium-based chiral IL 4a led to a splitting of 19.6 $\mathrm{Hz}$ in toluene (Fig. 5), whereas the use of 8 resulted in a

\begin{tabular}{ccc} 
Entry & {$[\mathbf{6 b}]$ (equiv.) } & $\boldsymbol{\Delta} \boldsymbol{\delta}(\mathbf{H z})$ \\
\hline 1 & 0.125 & 18.7 \\
2 & 0.25 & 23.1 \\
3 & 0.5 & 20 \\
4 & 1 & 22.8 \\
5 & 2 & 23.7 \\
6 & 3 & 21.4 \\
7 & 4 & 12.7 \\
8 & 5 & 8.8 \\
9 & 6 & 3.8
\end{tabular}

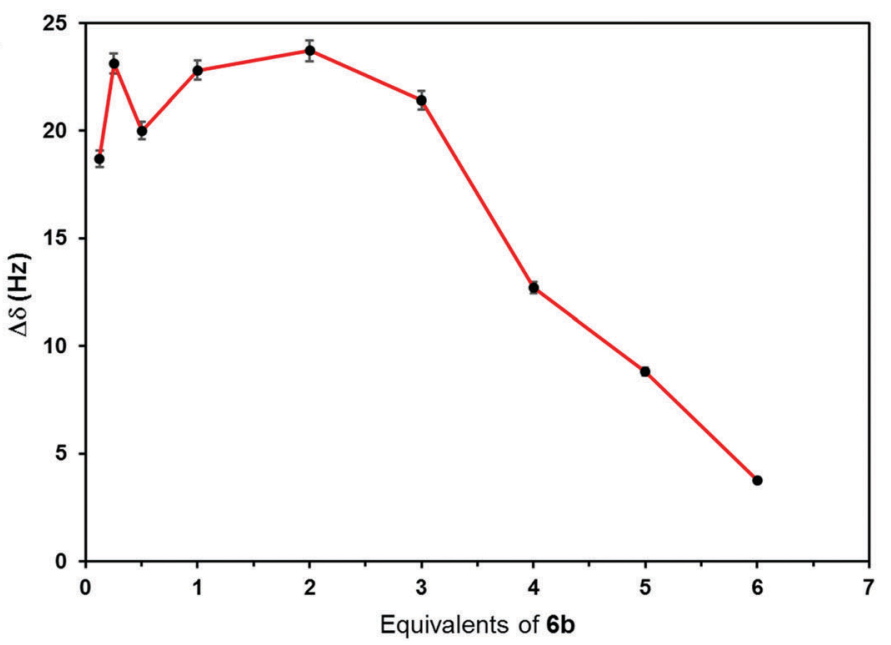

Fig. $3{ }^{19}$ F NMR chemical shift (recorded in toluene- $d_{8}$ ) of racemic Mosher's acid potassium salt in the presence of different amounts of $\mathbf{6} \mathbf{b}$. 


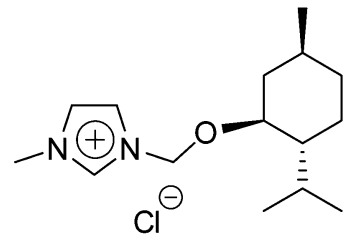

8

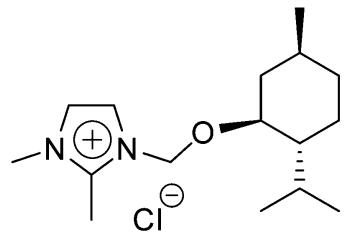

9
Fig. 4 Chiral ILs 8 and 9

similar discrimination (Fig. 5, $19.9 \mathrm{~Hz}$ ). Consequently, the formation of the diastereomeric adduct is not attributable to the $\pi-\pi$ stacking interactions between the phenyl groups of racemic substrate and chiral IL. Interestingly, no splitting was observed with 9 (Fig. 5), for which the hydrogen $\mathrm{H}-\mathrm{C} 2$ was replaced by a methyl group. This proves that the chiral IL interact with the Mosher's acid potassium salt through hydrogen bonding with the hydrogen atom located in $\mathrm{C} 2$ position of the imidazolium ring. This is one of the rare cases in which clear experimental evidences of the supramolecular interactions responsible for chiral recognition are observed.

Next, we studied the role of solvents and nature of chiral ILs on the extent of splitting of $\mathrm{CF}_{3}$ signal, since the strength of ion pairs are dependent on the polarity of the solvent employed. ${ }^{19}$ The experiments were conducted using different deuterated solvents but splitting was only observed in $\mathrm{CDCl}_{3}$ and toluene$\mathrm{d}_{8}$ (Table 2), while no splitting was detected when more polar solvents such as $\mathrm{D}_{2} \mathrm{O}, \mathrm{MeOD}$ and $\mathrm{CD}_{3} \mathrm{CN}$ were used. Consequently, it was realized that the solvent strongly affects the formation of the diastereomeric adduct and a reduction in its polarity probably increase the strength of the hydrogen bonding (and contact ion pair) ${ }^{20}$ and thus the interaction between the molecules of IL and Mosher's acid derivative. ${ }^{18}$ In most cases, changing the solvent to toluene leads to an
Table 2 Splitting of $\mathrm{CF}_{3}$ NMR signals of racemic Mosher's acid potassium salt in the presence of non-racemic $\mathrm{IL}^{2}$

\begin{tabular}{llllll}
\hline & & & & \multicolumn{2}{c}{$\Delta \delta^{b}(\mathrm{~Hz})$} \\
\cline { 5 - 6 } Entry & Non-racemic IL & Precursor alcohol & $\mathrm{X}$ & $\mathrm{CDCl}_{3}$ & Toluene \\
\hline $\mathbf{1}$ & $\mathbf{4 a}$ & (+)-Menthol & $\mathrm{Cl}$ & 9.0 & 19.6 \\
2 & $\mathbf{5 a}$ & (+)-Menthol & $\mathrm{BF}_{4}$ & 10.6 & 19.0 \\
3 & $\mathbf{6 a}$ & (+)-Menthol & $\mathrm{PF}_{6}$ & 11.6 & 11.3 \\
4 & $\mathbf{7 a}$ & (+)-Menthol & $\mathrm{NTf}_{2}$ & $\mathrm{NS}$ & $\mathrm{NS}$ \\
5 & $\mathbf{4 b}$ & (+)-Fenchol & $\mathrm{Cl}$ & 7.2 & 15.0 \\
6 & $\mathbf{5 b}$ & (+)-Fenchol & $\mathrm{BF}_{4}$ & 9.7 & 19.0 \\
7 & $\mathbf{6 b}$ & (+)-Fenchol & $\mathrm{PF}_{6}$ & 12.3 & 23.7 \\
8 & $\mathbf{7 b}$ & (+)-Fenchol & $\mathrm{NTf}_{2}$ & $\mathrm{NS}$ & $\mathrm{NS}$ \\
9 & $\mathbf{4 c}$ & (+)-Isopinocampheol & $\mathrm{Cl}_{1}$ & 11.3 & 11.5 \\
10 & $\mathbf{5 c}$ & (+)-Isopinocampheol & $\mathrm{BF}_{4}$ & $\mathrm{NS}$ & 15.3 \\
11 & $\mathbf{6 c}$ & (+)-Isopinocampheol & $\mathrm{PF}_{6}$ & $\mathrm{NS}$ & 8.6 \\
12 & $\mathbf{7 c}$ & (+)-Isopinocampheol & $\mathrm{NTf}_{2}$ & $\mathrm{NS}$ & $\mathrm{NS}$
\end{tabular}

${ }^{a}$ Reagents and conditions: non-racemic IL (2 equiv.), racemic Mosher's acid potassium salt (1 equiv.), deuterated solvent $(0.6 \mathrm{~mL})$. NS: no splitting. ${ }^{b}$ Uncertainty for $\Delta \delta: \pm 2 \%$.

increase in splitting of the ${ }^{19} \mathrm{~F}$ NMR signal of the racemic Mosher's acid potassium salt in comparison with $\mathrm{CDCl}_{3}$ (Table 2). For instance, chiral ILs 4-5a and 5-6b produced a splitting $>8$ units higher in toluene than those obtained in $\mathrm{CDCl}_{3}$ (entries 1 and 2). Similarly, the use of chiral ILs 5c and $\mathbf{6 c}$ resulted in a splitting of 15.3 and $8.6 \mathrm{~Hz}$ in toluene, respectively, whereas no splitting was observed when $\mathrm{CDCl}_{3}$ was utilized as solvent (entries 10 and 11).

The magnitude of the splitting is also affected by the type of anion forming the chiral IL used, and it appears to be related with the strength of the contact ion pair. In general, $\mathrm{Cl}^{-}, \mathrm{BF}_{4}{ }^{-}$and $\mathrm{PF}_{6}{ }^{-}$based salts form relatively strong ion pairs ${ }^{21}$ and provided a good discrimination, whereas no splitting was observed for hydrophobic ILs prepared with $\mathrm{NTf}_{2}{ }^{-}$as counteranion, which possess a weaker cation-anion interaction (entries 4, 8 and 12). Regarding the cation, chiral ILs derived from (+)-menthol and

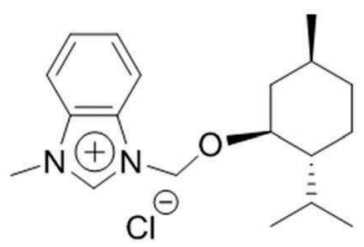

$\Delta \delta=19.6 \mathrm{~Hz}$

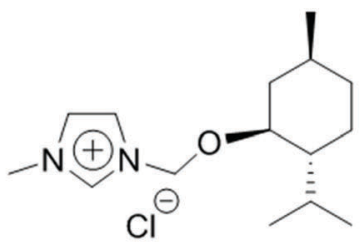

$\Delta \delta=19.9 \mathrm{~Hz}$

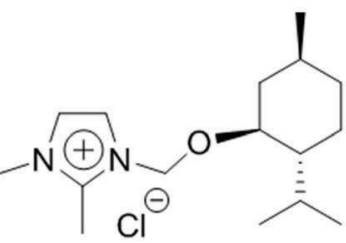

$\Delta \delta=0 \mathrm{~Hz}$

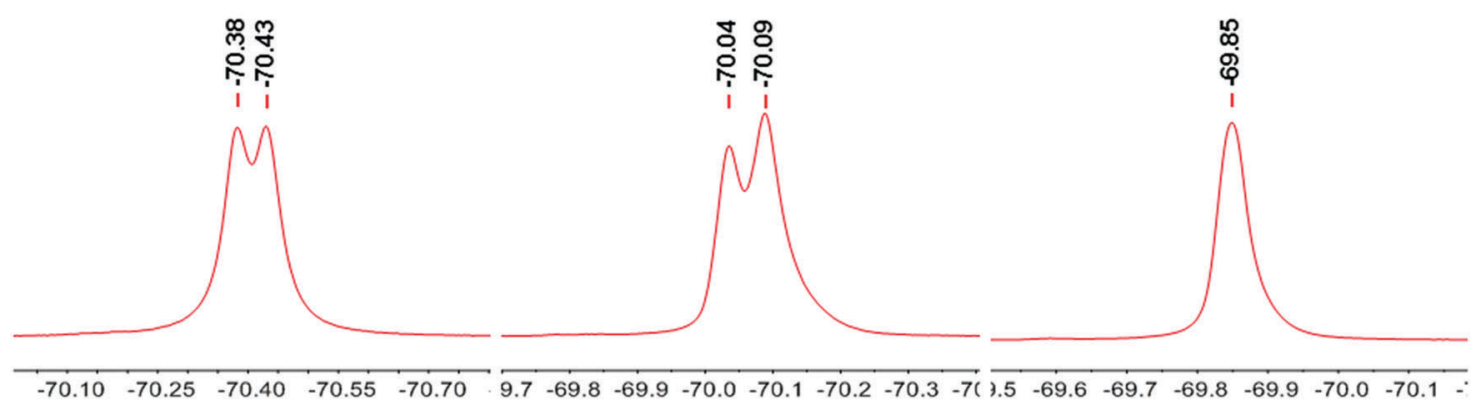

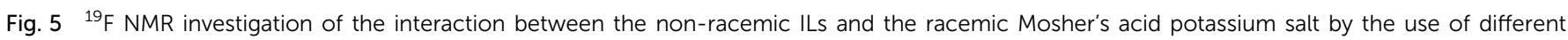
imidazolium-based ILs. 

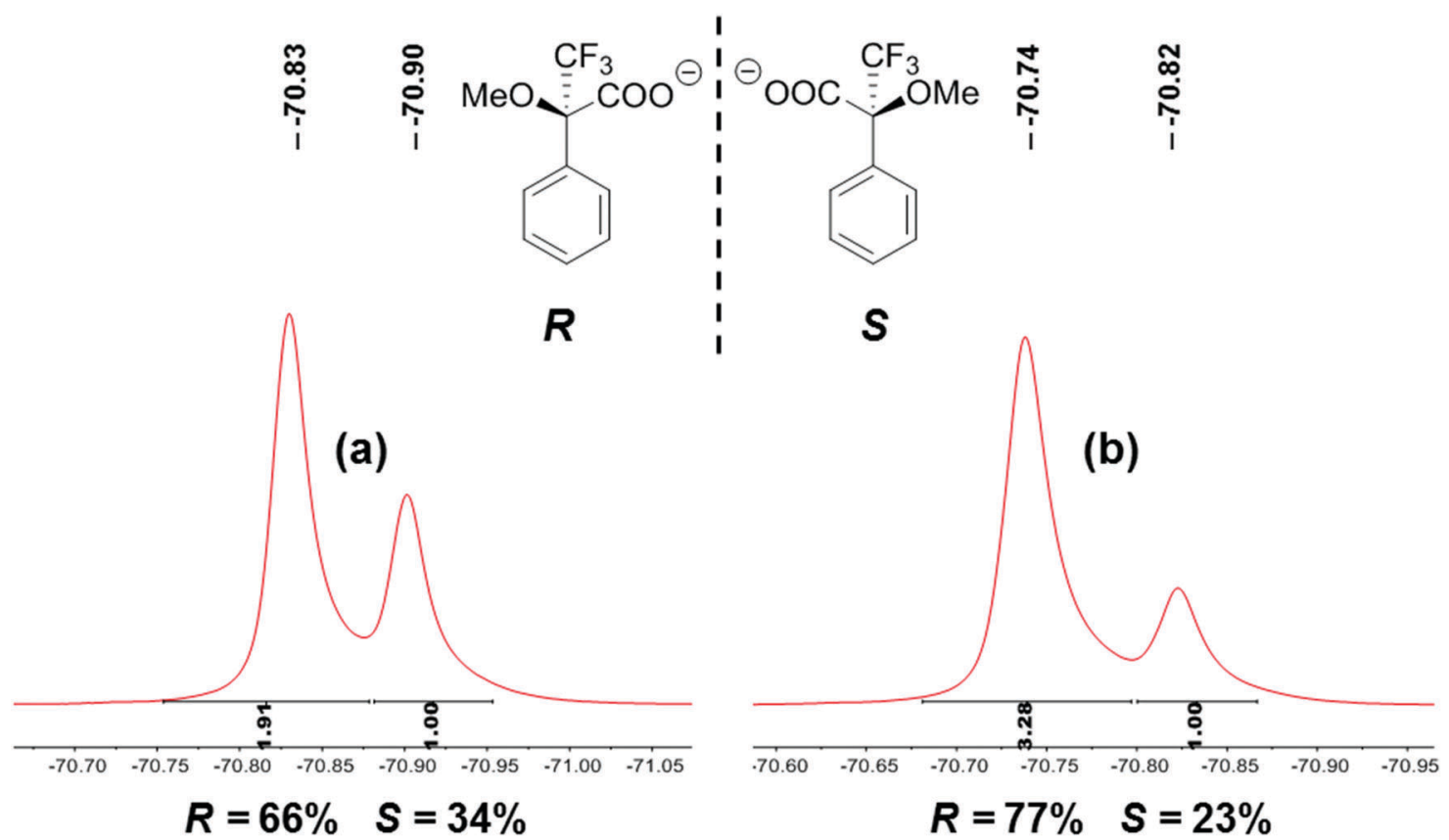

Fig. $6{ }^{19} \mathrm{~F}$ NMR spectra and determination of $\%$ ee values of enantioenriched samples of Mosher's acid potassium salt. (a) $R / S=2: 1$, (b) $R / S=4: 1$.

(+)-fenchol led to a similar splitting of the ${ }^{19} \mathrm{~F}$ NMR signal (entries 1-8), while the values observed for ILs prepared from (+)-isopinocampheol were lower (entries 9-12). In this context, the maximum splitting of $\mathrm{CF}_{3}$ signal was obtained for $\mathbf{6 b}$ (derived from (+)-fenchol), with $\Delta \delta=23.7 \mathrm{~Hz}$ (entry 7). This could be due to the higher steric impediment produced by the proximity of methyl groups of fenchol to the benzimidazolium ring in comparison with menthol and isopinocampheol.

The high chiral discrimination induced by ILs 4-7 encouraged us to evaluate their use for the determination of the enantiomeric excess of enantioenriched samples of Mosher's acid salt. Two samples with approximately $R / S=2: 1$ and $R / S=4: 1$ were prepared through the addition of $(R)$-Mosher's acid salt to the corresponding racemic salt. The integration of $\mathrm{CF}_{3}$ signals observed in the ${ }^{19} \mathrm{~F}$ NMR spectra provided the almost exact ratio of each enantiomer in the samples (Fig. 6). Consequently, the ILs described herein can be successfully employed to determine the ee value of chiral samples.

\section{Conclusions}

In summary, we have successfully designed and prepared a new family of twelve benzimidazolium-based non-racemic ILs through a three step synthetic methodology under solvent-free conditions. An exhaustive characterization was carried out by different techniques, which enabled us to confirm the structures of obtained ILs. The non-racemic ILs were found to be efficient chiral shift agents for the chiral recognition of racemic mixtures of Mosher's acid potassium salt by ${ }^{19} \mathrm{~F}$ NMR spectroscopy. In addition, experimental studies showed that the formation of the diastereomeric adduct is attributable to the interaction of the IL with the Mosher's acid potassium salt through hydrogen bonding with the more acidic hydrogen located in $\mathrm{C} 2$ position of the imidazolium ring. The effectiveness of the chiral recognition is directly related with the strength of the IL contact ion pair. Finally, the ILs demonstrated their potential for the determination of the enantiomeric excess of enantioenriched samples of Mosher's acid salt. In conclusion, these new benzimidazolium-based non-racemic ILs have shown their merit as chiral agents for enantiorecognition, which may inspire the design of new ILs with applications in chiral separation techniques.

\section{Conflicts of interest}

There are no conflicts of interest to declare.

\section{Acknowledgements}

Salma Mumtaz acknowledges HEC Pakistan for financial support under IRSIP program. Prof. Jairton Dupont gratefully thank support from the EPSRC. Dr Israel Cano acknowledges financial support from the European Community through a Marie Skłodowska-Curie Individual Fellowships (IF-EF; Programme/Call: H2020-MSCA-IF-2015; Proposal No: 704710-Sdchirnanocat).

\section{References}

1 (a) T. Welton, Chem. Rev., 1999, 99, 2071-2084; (b) P. Wasserscheid and W. Keim, Angew. Chem., Int. Ed., 2000, 39, 3772-3789; (c) R. Sheldon, Chem. Commun., 2001, 2399-2407; (d) N. Jain, A. Kumar, S. Chauhan and S. M. S. Chauhan, Tetrahedron, 2005, 61, 1015-1060; (e) D. Rooney, J. Jacquemin and R. Gardas, Top. Curr. Chem., 
2009, 290, 185-212; $(f)$ S. Aparicio, M. Atilhan and F. Karadas, Ind. Eng. Chem. Res., 2010, 49, 9580-9595; (g) D. D. Irge, Am. J. Phys. Chem., 2016, 5, 74-79.

2 (a) C. Baudequin, J. Baudoux, J. Levillain, D. Cahard, A.-C. Gaumont and J.-C. Plaquevent, Tetrahedron: Asymmetry, 2003, 14, 3081-3093; (b) J. Ding and D. W. Armstrong, Chirality, 2005, 17, 281-292.

3 (a) A. Paczal and A. Kotschy, Monatsh. Chem., 2007, 138, 1115-1123; (b) S. Luo, L. Zhang and J.-P. Cheng, Chem. - Asian J., 2009, 4, 1184-1195; (c) S. Payra, A. Saha and S. Banerjee, Curr. Organocatal., 2017, 4, 4-32; (d) A. Singh and H. K. Chopra, Curr. Org. Synth., 2017, 14, 488-510.

4 (a) C. Baudequin, D. Bregeon, J. Levillain, F. Guillen, J.-C. Plaquevent and A.-C. Gaumont, Tetrahedron: Asymmetry, 2005, 16, 3921-3945; (b) K. Bica and P. Gaertner, Eur. J. Org. Chem., 2008, 3235-3250; (c) T. Payagala and D. W. Armstrong, Chirality, 2012, 24, 17-53.

5 (a) H. Ohno and K. Fukumoto, Acc. Chem. Res., 2007, 40, 1122-1129; (b) D. K. Bwambok, S. K. Challa, M. Lowry and I. M. Warner, Anal. Chem., 2010, 82, 5028-5037; (c) X. Chen, X. Li, A. Hu and F. Wang, Tetrahedron: Asymmetry, 2008, 19, 1-14; (d) L. Gonzalez, B. Altava, M. Bolte, M. I. Burguete, E. García-Verdugo and S. V. Luis, Eur. J. Org. Chem., 2012, 4996-5009; (e) M. B. A. Rahman, K. Jumbri, M. Basri, E. Abdulmalek, K. Sirat and A. B. Salleh, Molecules, 2010, 15, 2388-2397.

6 (a) V. Kumar, C. Pei, C. E. Olsen, S. J. C. Schäffer, V. S. Parmar and S. V. Malhotra, Tetrahedron: Asymmetry, 2008, 19, 664-671; (b) O. N. V. Buu, A. Aupoix, N. D. T. Hong and G. Vo-Thanh, New J. Chem., 2009, 33, 2060-2072; (c) Z. Zhou, J. Qiu, L. Xie, F. Du, G. Xu, Y. Xie and Q. Ling, Catal. Lett., 2014, 144, 1911-1918; (d) A. Costa, A. Forte, K. Zalewska, G. Tiago, Z. Petrovski and L. C. Branco, Green Chem. Lett. Rev., 2015, 8, 8-12.

7 (a) R. A. F. Matos and C. K. Z. Andrade, Tetrahedron Lett., 2008, 49, 1652-1655; (b) D. Nageshwar, D. M. Rao and P. V. R. Acharyulu, Synth. Commun., 2009, 39, 3357-3368; (c) J. Feder-Kubis, M. Kubicki and J. Pernak, Tetrahedron: Asymmetry, 2010, 21, 2709-2718; (d) T. Heckel, A. Winkel and R. Wilhelm, Tetrahedron: Asymmetry, 2013, 24, 1127-1133.

8 (a) Q. Liu, K. Wu, F. Tang, L. Yao, F. Yang, Z. Nie and S. Yao, Chem. - Eur. J., 2009, 15, 9889-9896; (b) Y. Yan-Xia, L. Jing and J. Xin-Yu, J. Cent. South Univ., 2013, 20, 1173-1177.
9 (a) T. Biedroń and P. Kubisa, Polym. Int., 2003, 52, 1584-1588; (b) H.-y. Ma, X.-h. Wan, X.-f. Chen and Q.-f. Zhou, Chin. J. Polym. Sci., 2003, 21, 265-270; (c) T. Biedroń and P. Kubisa, J. Polym. Sci., Part A: Polym. Chem., 2005, 43, 3454-3459.

10 (a) A. Berthod, L. He and D. W. Armstrong, Chromatographia, 2001, 53, 63-68; (b) Z. Zhou, X. Li, X. Chen and X. Hao, Anal. Chim. Acta, 2010, 678, 208-214; (c) L. M. Yuan, Y. Han, Y. Zhou, X. Meng, Z. Y. Li, M. Zi and Y. X. Chang, Anal. Lett., 2006, 39, 1439-1449; (d) X. Sun, J. Xu, X. Zhao, Y. Zhai and J. Xing, Chromatographia, 2013, 76, 1013-1019; (e) C. P. KapnissiChristodoulou, I. J. Stavrou and M. C. Mavroudi, J. Chromatogr. A, 2014, 1363, 2-10.

11 (a) Y. Francois, A. Varenne, E. Juillerat, D. Villemin and P. Gareil, J. Chromatogr. A, 2007, 1155, 134-141; (b) J. Yu, L. Zuo, H. Liu, L. Zhang and X. Guo, Biomed. Chromatogr., 2013, 27, 1027-1033; (c) J. Zhang, Y. Du, Q. Zhang, J. Chen, G. Xu, T. Yu and X. Hua, J. Chromatogr. A, 2013, 1316, 119-126; (d) J. Zhang, Y. Du, Q. Zhang and Y. Lei, Talanta, 2014, 119, 193-201.

12 A. Winkel, P. V. G. Reddy and R. Wilhelm, Synthesis, 2008, 999-1016.

13 M. L. Patil and H. Sasai, Chem. Rec., 2008, 8, 98-108.

14 G. K. E. Scriba, J. Chromatogr. A, 2016, 1467, 56-78.

15 P. Wasserscheid, A. Bösmann and C. Bolm, Chem. Commun., 2002, 200-201.

16 S. Mumtaz, S. W. Khan, J. H. Zaidi, A. Iqbal, Z. M. Cheema, K. M. Khan and S. Perveen, Lett. Org. Chem., 2013, 10, 578-583.

17 (a) H. Clevier, L. Boulanger, N. Audic, L. Toupet, M. Mauduit and J.-C. Guillemin, Chem. Commun., 2004, 1224-1225; (b) B. Altava, D. S. Barbosa, M. I. Burguete, J. Escorihuela and S. V. Luis, Tetrahedron: Asymmetry, 2009, 20, 999-1003; (c) R. Jayachandra and S. R. Reddy, RSC Adv., 2016, 6, 39758-39761.

18 A. Winkel and R. Wilhelm, Eur. J. Org. Chem., 2010, 5817-5824.

19 M. Zanatta, A. L. Girard, N. M. Simon, G. Ebeling, H. K. Stassen, P. R. Livotto, F. P. dos Santos and J. Dupont, Angew. Chem., Int. Ed., 2014, 53, 12817-12821.

20 L. Santos, B. Neto, C. Consorti, C. Pavam, W. Almeida, F. Coelho, J. Dupont and M. Eberlin, J. Phys. Org. Chem., 2006, 19, 731-737.

21 H. K. Stassen, R. Ludwig, A. Wulf and J. Dupont, Chem. - Eur. J., 2015, 21, 8324-8335. 